\title{
Results from four pharmacokinetic studies of the granisetron transdermal system
}

This article was published in the following Dove Press journal:

Research and Reports in Transdermal Drug Delivery

24 July 2013

Number of times this article has been viewed

\author{
Sally T Haislip' \\ James W Gilmore' \\ Julian D Howell ${ }^{2}$ \\ 'Georgia Cancer Specialists, Atlanta, \\ GA, USA $;{ }^{2}$ Clinical Development, \\ ProStrakan, Galashiels, UK
}

Introduction: Sancuso ${ }^{\circledR}$ (granisetron transdermal system [GTDS]) is the first antiemetic agent for chemotherapy-induced nausea and vomiting and is available as a $52 \mathrm{~cm}^{2}$ patch containing $34.3 \mathrm{mg}$ of granisetron delivered transdermally at $3.1 \mathrm{mg} / 24$ hours for up to 7 days. Four Phase I studies were performed to assess the pharmacokinetic profile of the GTDS.

Methods: The four Phase I studies in healthy adult volunteers were conducted to investigate the pharmacokinetics of GTDS with respect to patch placement on the body (study 1); age, body mass index, and tricep skinfold thickness (as a surrogate for cachectic or obese patients) (study 2); external heat (study 3); and consecutive GTDS patch administration or coadministration of GTDS with intravenous granisetron (study 4).

Results: In study $1(\mathrm{n}=12)$, the systemic bioavailability of granisetron from a GTDS patch applied to the abdomen was similar to that seen after application to the upper arm. Findings from study $2(n=60)$ showed no effect of age, body mass index, or skinfold thickness on the pharmacokinetics of transdermally administered granisetron. The application of external heat to the GTDS patch in study $3(n=16)$ elicited a small increase in granisetron flux but had no significant effect on GTDS pharmacokinetics or adverse events. In study $4(n=12)$, consecutive GTDS patch administration, or coadministration of the GTDS patch with intravenous granisetron, demonstrated both immediate and extended granisetron delivery with evidence of minimal accumulation.

Conclusion: Findings from these four studies suggest that no GTDS dose adjustments are needed for patient age, body mass index, or tricep skinfold thickness. Also, should external heat (eg, sunlight or warm showers) be applied to the GTDS short-tem, there are unlikely to be significant adverse consequences. Both sequential GTDS patch administration and coadministration with intravenous granisetron may be feasible if clinically warranted.

Keywords: transdermal, chemotherapy-induced nausea and vomiting, antiemetic, granisetron, pharmacokinetics

\section{Introduction}

Chemotherapy-induced nausea and vomiting (CINV) is one of the most distressing conditions for patients undergoing cancer chemotherapy and remains a common adverse event, despite the use of antiemetic therapy. ${ }^{1-3}$ CINV can have a negative effect on patients' quality of life and adherence to chemotherapy., Chemotherapy delays and dosage reductions resulting from CINV may, in turn, reduce treatment efficacy and potentially reduce patient survival. ${ }^{3,6}$ Moreover, there is a small but growing number of multiday regimens, some of which are combinations of cytotoxic and targeted therapies. These multiday regimens present the added challenge of potentially eliciting overlapping episodes of acute and delayed CINV.
Correspondence: Sally T Haislip RP Oncology Research, Georgia Cancer Specialists, 1835 Savoy Drive, Suite 300 Atlanta, GA 3034I, USA

Tel +l 7704969457

Fax +I 7704918670

Email sally.haislip@gacancer.com 
Sancuso $^{\circledR}$ (granisetron transdermal system [GTDS]; ProStrakan, Inc, Bridgewater, NJ, USA) is the first antiemetic agent for CINV that is available in a transdermal formulation. ${ }^{7,8}$ Granisetron is a selective 5-hydroxytryptamine 3 receptor antagonist ${ }^{9}$ and is available in both oral and intravenous (IV) formulations. ${ }^{10,11}$ GTDS is indicated for the prevention of nausea and vomiting in patients receiving highly or moderately emetogenic chemotherapy regimens of up to five consecutive days in duration. ${ }^{7}$ GTDS and other 5-hydroxytryptamine 3 receptor antagonists are included in both the National Comprehensive Cancer Network and the American Society of Clinical Oncology antiemetic guidelines as first-line options in preventive antiemetic therapy along with neurokinin-1 antagonists with or without dexamethasone, depending on risk of emesis. ${ }^{12,13}$

The GTDS is a $52 \mathrm{~cm}^{2}$ patch containing $34.3 \mathrm{mg}$ of granisetron, which is delivered transdermally as $3.1 \mathrm{mg} / 24$ hours for up to 7 days. The GTDS is applied to the upper outer arm at least 24 hours before chemotherapy administration. ${ }^{7}$ The GTDS delivers granisetron using a matrix diffusion method that includes a stable matrix of granisetron base ( $6 \%$ weight/ weight) and a commercially available pressure-sensitive adhesive (DURO-TAK, Henkel, Düsseldorf, Germany). The sustained release of granisetron for up to 7 days eliminates the need for repeated IV or oral administration of antiemetics during multiple-day chemotherapy or multiple chemotherapy cycles. $^{9}$

GTDS has been shown to be effective in the treatment of CINV and noninferior to oral granisetron $(2 \mathrm{mg})$ in a multicenter, randomized, double-blind, Phase III trial in 641 patients with cancer receiving moderately or highly emetogenic multiday chemotherapy. ${ }^{14}$ In this study, $60 \%$ of patients receiving GTDS 24-48 hours before the start of chemotherapy achieved complete control of CINV from the first dose of chemotherapy until 24 hours after the last dose during up to five consecutive days of chemotherapy, and control rates on individual days were greater than $80 \%$. GTDS was well tolerated; most adverse events were mild or moderate in severity, and constipation was the most commonly reported adverse event in both groups that was related to antiemetic treatment. ${ }^{14}$

The 5-hydroxytryptamine 3 receptor antagonists have been associated with potential cardiac adverse events, specifically QT interval changes, and the prescribing information for several of these agents contains precautions or warnings relating to cardiac toxicity. ${ }^{10,11,15,16}$ Electrocardiographic (ECG) effects were monitored in the Phase III trial, but no clinically significant ECG changes were reported for either oral or transdermal granisetron. ${ }^{14}$ This is supported by findings from a Phase I, single-site, single-blind, randomized, placebo- and positive-controlled, four-arm, parallel study (thorough QT/QTc study), which found no significant effects on ECG parameters, derived ECG parameters, or the incidences of ST-segment and T-wave abnormalities, and no significant prolongation in corrected QT interval (QTcF). ${ }^{17}$

Certain aspects of the pharmacologic and pharmacokinetic profile of GTDS are particularly relevant to CINV prophylaxis and the appropriate use of GTDS in clinical practice. Four Phase I clinical studies were designed to investigate the effects of patch placement (study 1); age, weight, body mass index (BMI), and tricep skinfold thickness (study 2); therapeutic and other exposure to heat (study 3); and concurrent use of the patch and IV therapy and consecutive patch use (study 4). All of these studies were conducted in accordance with local and national ethical standards, including the Declaration of Helsinki, and written informed consent was obtained from all participating subjects. The results of these four studies are reported here.

\section{Study I: GTDS patch placement}

The effectiveness of the patch when applied to different sites on the body is of interest as disease or its treatment in some patients may limit application sites, such as the occurrence of arm edema after axilla surgery in breast cancer patients.

\section{Methods}

The pharmacokinetics of the GTDS when applied to the abdomen was investigated in a single-center, single-dose, placebo-controlled Phase I study in healthy volunteers in Germany (Applied Analytical Industries Deutschland code NA099). Six healthy men and six healthy women aged 18-40 years were enrolled. GTDS and placebo patches were applied to either side of the upper abdomen of each subject and remained in place for 5 days. The GTDS patch contained granisetron $660 \mu \mathrm{g} / \mathrm{cm}^{2}$ and had a total area of $15 \mathrm{~cm}^{2}$, making the maximum exposure (if all the granisetron was absorbed) $9.9 \mathrm{mg}$ over a 5-day period. The primary objective of the study was to confirm the systemic bioavailability of granisetron delivered from the GTDS, and a secondary objective was to assess the pharmacokinetic profile of granisetron delivered from the GTDS.

Blood samples were taken at predetermined time points over the 120-hour period that the GTDS or placebo patch remained in place and at two additional time points after the patch was removed (126 and 132 hours). 
Plasma concentrations of granisetron were determined by high-performance liquid chromatography using fluorometric detection.

\section{Results}

Pharmacokinetic parameters were available for eleven of the 12 subjects enrolled; granisetron levels were below the limit of quantification in one subject. Pharmacokinetic parameters are summarized in Table 1. Mean maximum granisetron concentration $\left(\mathrm{C}_{\max }\right)$ was $1.9 \mathrm{ng} / \mathrm{mL}$ (standard deviation [SD] $1.3 \mathrm{ng} / \mathrm{mL})$, and mean time to $\mathrm{C}_{\max }\left(\mathrm{t}_{\max }\right)$ was 57 hours (range 30-126 hours; SD 28 hours), showing sustained delivery over 5 days.

\section{Conclusion}

The systemic bioavailability of granisetron delivered from the GTDS patch applied to the abdomen is similar to that seen when the patch is applied to the upper arm, ${ }^{18}$ suggesting that abdominal application of the patch is an appropriate alternative for patients whose disease or treatment prevents application on the upper arm.

A comparison of $\mathrm{C}_{\max }$ for the $15 \mathrm{~cm}^{2}$ patch and the $52 \mathrm{~cm}^{2}$ patch (the approved GTDS patch containing $34.3 \mathrm{mg}$ of granisetron) showed that the mean dose-adjusted $\mathrm{C}_{\max }$ was $6.6 \mathrm{ng} / \mathrm{mL}$ for the $15 \mathrm{~cm}^{2}$ patch compared with $5.0 \mathrm{ng} / \mathrm{mL}$ for the $52 \mathrm{~cm}^{2}$ patch.

\section{Study 2: age, BMI, and tricep skinfold thickness}

Patient age is important to cancer therapeutics because many types of cancer are diagnosed in patients aged 65 years or older. Patient BMI is also an important consideration both because of the increased prevalence of obesity and because BMIs among patients with cancer can

Table I Granisetron pharmacokinetic parameters for the $15 \mathrm{~cm}^{2}$ GTDS patch during abdominal placement

\begin{tabular}{llll}
\hline Parameter & $\begin{array}{l}\mathbf{A U C}_{\mathbf{0 - 1 3 2}} \\
\text { (h.ng/mL) }\end{array}$ & $\begin{array}{l}\mathbf{C}_{\max } \\
\text { (ng/mL) }\end{array}$ & $\begin{array}{l}\mathbf{t}_{\text {max }} \\
\text { (hour) }\end{array}$ \\
\hline $\mathrm{N}$ & $\mathrm{II}$ & $\mathrm{II}$ & $\mathrm{II}$ \\
Median & $\mathrm{II}$ & $\mathrm{I} .5$ & 48 \\
Mean & $\mathrm{I} 48$ & $\mathrm{I} .9$ & 57 \\
Standard deviation & $\mathrm{II}$ & $\mathrm{I} .3$ & 28 \\
CV\% & 79 & 72 & 50 \\
Geometric mean & $\mathrm{II}$ & $\mathrm{I} .5$ & - \\
Geometric mean CV\% & 88 & 72 & - \\
\hline
\end{tabular}

Abbreviations: $\% \mathrm{CV}$, percentage coefficient of variation; $\mathrm{AUC}_{0-132}$, area under the concentration-time curve from 0 to 132 hours; $C_{\max }$, maximum plasma concentration; GTDS, granisetron transdermal system; N, number of subjects; $\mathrm{t}_{\max }$, time to maximum plasma concentration. be very low owing to reduced oral nutrition subsequent to gastrointestinal tumors, CINV-related anorexia, or cancer-related weight loss. ${ }^{19}$ Tricep skinfold thickness is relevant to determining if subcutaneous fat levels affect the absorption of granisetron from the GTDS; differences in subcutaneous fat and skin condition may affect individual pharmacokinetic profiles. Clinical study data from patients with altered skin integrity are limited as these patients are usually of advanced age or have poor nutritional status related to chronic illness. ${ }^{19}$

\section{Methods}

All 12 subjects were Caucasian and had a median age of 31.5 years. A single-center, open-label, Phase I study (NCT00868764) was conducted in two parts to examine the effects of age (part I), BMI (part II), and tricep skinfold thickness (surrogate measure of subcutaneous fat) on GTDS pharmacokinetics in 60 healthy adults. Subjects were selected and grouped based on demographic criteria: elderly $(n=24$; aged $\geq 65$ years; BMI of $20.0-29.9 \mathrm{~kg} / \mathrm{m}^{2}$ ), younger age/ control ( $\mathrm{n}=6$; aged $\geq 18-45 \mathrm{y} ;$ BMI $\geq 20.0-29.9 \mathrm{~kg} / \mathrm{m}^{2}$ ), underweight $\left(\mathrm{n}=12\right.$; aged $18-60$ years; BMI $<19.5 \mathrm{~kg} / \mathrm{m}^{2}$ [men] or $<18.5 \mathrm{~kg} / \mathrm{m}^{2}$ [women]), normal weight ( $\mathrm{n}=6$; age $18-60$ years; $\left.B M I \geq 20.0-24.9 \mathrm{~kg} / \mathrm{m}^{2}\right)$, and obese $(\mathrm{n}=12$; age $18-60$ years; $\mathrm{BMI} \geq 30.0-39.9 \mathrm{~kg} / \mathrm{m}^{2}$ ).

Subjects were admitted to the clinic the day before dosing and had a GTDS patch applied on day 1 for 7 days. Subjects remained resident until 8 hours after patch application for blood sampling (on day 1 at -1 hour and at 8, 24, 48, 72, 96, 120, 144, 168, and 192 hours after patch application) and safety assessments. Subjects returned for further assessments for up to 216 hours after patch application and for patch removal on day 8 . Tricep skinfold thickness was measured in all subjects at screening. Follow-up evaluations were performed no more than 14 days after the final assessment. The following pharmacokinetic parameters were measured: area under the concentration-time curve from time 0 to infinity $\left(\mathrm{AUC}_{0-\infty}\right)$ and from time 0 to the time point of the last quantifiable concentration $\left(\mathrm{AUC}_{0-\mathrm{z}}\right), \mathrm{C}_{\max }$, average plasma concentration $\left(\mathrm{C}_{\text {avg }}\right), \mathrm{t}_{\max }$, and elimination half-life $\left(\mathrm{t}_{1 / 2}\right)$. Pearson correlations were conducted to explore correlations between three pharmacokinetic parameters $\left(\mathrm{C}_{\max }, \mathrm{AUC}_{0-\mathrm{z}}\right.$, and $\mathrm{C}_{\mathrm{avg}}$ [on the $\log _{10}$ scale]) and age, BMI, and tricep skinfold thickness. ${ }^{20} \mathrm{~A}$ multiple linear regression analysis was performed on the same pharmacokinetic parameters to determine the predictive power of age, BMI, and tricep skinfold thickness, allowing for subject height, weight, race, alcohol intake, and smoking status. ${ }^{20}$ 


\section{Results}

Comparable pharmacokinetic profiles were observed for the elderly (aged $\geq 65$ years) and control groups (aged $\geq 18-45$ years), as well as for the three BMI groups (underweight, normal, and obese) (Table 2). No significant differences were observed between age groups or between BMI groups. Systemic exposure to granisetron was comparable between the control and elderly groups and between the BMI groups, and no significant correlations were noted between age or BMI and standard pharmacokinetic parameters for the GTDS. Similarly, tricep skinfold thickness did not significantly correlate with $\mathrm{C}_{\max }, \mathrm{AUC}_{0-\mathrm{z}}$ and $\mathrm{AUC}_{0-\infty}$ or $\mathrm{C}_{\text {avg }}{ }^{20}$ Pearson correlations and multiple regression analysis were performed on 58 of the 60 subjects, who had a median age of 54 years (range 18-84 years), median BMI of $25 \mathrm{~kg}$ / $\mathrm{m}^{2}\left(16-39 \mathrm{~kg} / \mathrm{m}^{2}\right)$, and median tricep skinfold thickness of $10 \mathrm{~mm}(2-20 \mathrm{~mm})$. No significant correlations were found between $\mathrm{C}_{\max }, \mathrm{AUC}_{0-\mathrm{z}}$, or $\mathrm{C}_{\text {avg }}$ and age, $\mathrm{BMI}$, or tricep skinfold thickness. Moreover, the multiple linear regression analysis found that age, BMI, and tricep skinfold thickness were not significant predictors of pharmacokinetic profile.

\section{Conclusion}

Age, BMI, and skinfold thickness did not affect the pharmacokinetic profile of granisetron administered from the GTDS, suggesting that no GTDS dose adjustments are needed for patient age or extremes of BMI. ${ }^{20}$

\section{Study 3: external heat}

Use of heat by patients with cancer is another source of possible variability in treatment efficacy with GTDS. Several clinical studies and case reports have shown that heat can increase drug absorption from transdermal patches. ${ }^{21-23}$
Higher temperatures can raise rates of drug flux owing to changes in drug solubility and membrane permeability. Temperature change also affects skin and blood vessel permeability as well as blood flow distribution and can cause vasodilation. Patients using GTDS could be exposed to sources of external heat such as sunlight, warm showers, or electric blankets used as local pain-relieving treatments, although current prescribing information advises against this exposure. Thus, it is important to examine whether external heat sources could increase granisetron absorption and expose patients to higher levels of drug than therapeutically intended.

\section{Methods}

The effect of locally applied heat on the pharmacokinetic profile of GTDS was evaluated in a single-center, open-label, randomized, crossover, Phase I study (NCT01073696) conducted in healthy men and women aged $18-45$ years. A GTDS patch was applied to the upper outer arm for 5 days, and a second patch was applied to the other arm for 5 days after a minimum washout of 14 days. Subjects were randomized 1:1 to have a Cura-Heat ${ }^{\circledR}$ Back and Shoulder pad (Kobayashi Healthcare Europe Ltd, London, UK), with a measured local temperature of approximately $42^{\circ} \mathrm{C}\left(107.6^{\circ} \mathrm{F}\right)$, applied over the patch during either the first or second patch application. This was left in place continuously for 4.5 hours daily for 5 days. Total study duration did not exceed 11 weeks.

On the morning of day 1 ( 0 hour), predose medical assessments were performed and a pharmacokinetic blood sample taken before the GTDS was applied. All subjects remained in the clinic until 8 hours after GTDS application for pharmacokinetic blood sampling (at 1, 2, 3, 4, 5, 6, 7, and 8 hours after application) and monitoring of adverse events and concomitant medications. Subjects returned to the clinic daily on days

Table 2 Plasma pharmacokinetic parameter estimates for granisetron by age and BMI after administration of the GTDS

\begin{tabular}{|c|c|c|c|c|c|c|c|}
\hline \multirow[t]{2}{*}{ Group } & \multirow[t]{2}{*}{$\mathbf{n}$} & \multicolumn{4}{|c|}{ Geometric mean (CV\%) } & \multirow{2}{*}{$\begin{array}{l}t_{\max } \text { hour } \\
\text { median (range) }\end{array}$} & \multirow{2}{*}{$\begin{array}{l}t_{1 / 2} \text { hour } \\
\text { mean (SD) }\end{array}$} \\
\hline & & $\begin{array}{l}\text { AUC }_{0-\infty} \\
(\mathrm{ng} \cdot \mathrm{h} / \mathrm{mL})\end{array}$ & $\begin{array}{l}\text { AUC }_{0-z} \\
(\mathrm{ng} \cdot \mathrm{h} / \mathrm{mL})\end{array}$ & $\begin{array}{l}C_{\max } \\
(\mathrm{ng} / \mathrm{mL})\end{array}$ & $\begin{array}{l}C_{\text {avg }} \\
(n g / m L)\end{array}$ & & \\
\hline \multicolumn{8}{|l|}{ Age } \\
\hline Control ( $\geq 18-45$ years) & 6 & $677.5(63.5)^{\mathrm{a}}$ & $519.6(55.6)$ & $4.16(53.1)$ & $2.93(56.5)$ & $60.14(48.00,96.00)$ & $44.55(12.48)^{\mathrm{a}}$ \\
\hline Elderly ( $\geq 65$ years) & 23 & $551.0(125.7)^{\mathrm{b}}$ & $443.7(124.5)$ & $3.42(125.0)$ & $2.46(130.0)$ & $72.00(48.00,192.00)$ & $48.72(13.25)^{b}$ \\
\hline \multicolumn{8}{|l|}{ BMI } \\
\hline $\begin{array}{l}\text { Underweight } \\
\left(<19.5 \mathrm{~kg} / \mathrm{m}^{2} \text { in men; }\right. \\
\left.<18.5 \mathrm{~kg} / \mathrm{m}^{2} \text { in women }\right)\end{array}$ & 12 & $843.5(97.7)^{c}$ & $637.8(88.6)^{c}$ & $5.83(100.2)$ & $3.84(88.6)$ & $72.00(24.00,120.00)$ & $62.99(43.70)^{c}$ \\
\hline Normal $\left(20.0-24.9 \mathrm{~kg} / \mathrm{m}^{2}\right)$ & 6 & $485.6(149.6)^{d}$ & $429.9(160.5)^{d}$ & $3.43(132.1)$ & $2.33(131.1)$ & $72.12(48.00,168.00)$ & $44.26(10.7 I)^{d}$ \\
\hline Obese $\left(30.0-39.9 \mathrm{~kg} / \mathrm{m}^{2}\right)$ & 12 & $692.6(82.8)$ & $613.0(93.9)$ & $5.15(102.7)$ & $3.55(97.4)$ & $72.00(48.00,120.00)$ & $45.29(20.73)$ \\
\hline
\end{tabular}

Notes: ${ }^{a} n=4 ;{ }^{b} n=21 ;{ }^{c} n=11 ;{ }^{d} n=5$.

Abbreviations: $\mathrm{AUC}_{0-\infty}$, area under the concentration-time curve from time 0 to infinity; $\mathrm{AUC}_{0-\mathrm{z}}$, area under the concentration-time curve from time 0 to the time point of the last quantifiable concentration; $\mathrm{BMI}$, body mass index; $\mathrm{C}_{\text {avg }}$, average plasma concentration; $\mathrm{C}_{\text {max }}$, maximum plasma concentration; $\mathrm{CV}$, coefficient of variation; $\mathrm{n}$, number of subjects; $t_{1 / 2}$, elimination half-life; $t_{\max }$, time to maximum plasma concentration. 
2-5 inclusive for reapplication of the Cura-Heat pad and for further blood sampling (at 24, 25, 26, 27, 28, 30, 48, 49, 50, $51,52,54,72,96$, and 120 hours after application) and safety assessments. Subjects remained in the clinic for the 4.5 hours during which the Cura-Heat pad was in place. All subjects once again returned to the clinic daily on days 6 to 9 inclusive for GTDS removal (day 6) and for further blood sampling (at 144, 168, and 192 hours after application) and safety assessments.

\section{Results}

Overall systemic exposure to granisetron was comparable between the GTDS alone and the GTDS plus Cura-Heat pad, indicating no overall effect of external heat on the pharmacokinetics of transdermal granisetron in this study (Figure 1). Application of external heat tended to result in earlier quantifiable granisetron levels; concentrations were quantifiable in 12 of the 16 subjects given the Cura-Heat pad after 6 hours, whereas concentrations were quantifiable in only seven of the 16 subjects given GTDS alone after 8 hours. Review of individual patient profiles at times of heat application also showed small increases in granisetron concentration that quickly returned to without-heat levels once the heat source was removed. Comparisons of geometric mean $\mathrm{C}_{\max }, \mathrm{C}_{\mathrm{avg}}$, and $\mathrm{AUC}_{0-\mathrm{z}}$ values indicated that systemic exposure was similar for both treatments (Table 3 ). In addition, no clinically significant differences between groups were observed between $t_{\max }$ and $t_{1 / 2}$, and no clinically significant differences were noted in rates or types of adverse events between the two treatments.

\section{Conclusion}

The application of external heat did not have any significant effects on the pharmacokinetic parameters of granisetron when administered via the GTDS, and no differences in adverse events were apparent. These data suggest that should

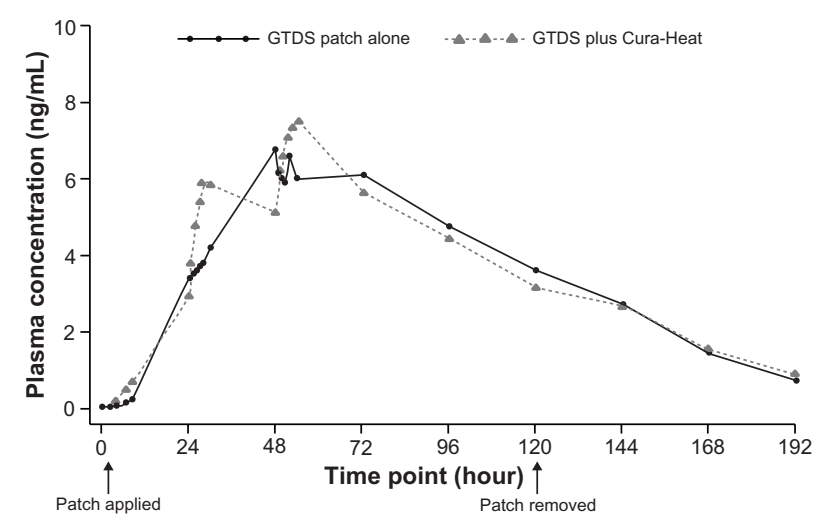

Figure I Granisetron plasma concentrations after administration of the GTDS with and without application of external heat.

Note: The Cura-Heat pad was applied for 4.5 hours each day of the 5 day study period. Abbreviation: GTDS, granisetron transdermal system. an external heat source - such as sunlight, warm showers, or electric blankets used as local pain-relieving treatments - be applied to the GTDS over a short period, there appear to be no clinically significant effects on granisetron absorption or patient exposure to the drug. However any heat exposure to GTDS is not recommended.

\section{Study 4: sequential GTDS patch administration and coadministration with IV granisetron}

Simultaneous administration of IV granisetron and the GTDS is worthy of investigation, as scheduling needs or urgency of treatment sometimes prevent patients from applying the patch 24-48 hours before beginning chemotherapy. Therefore, it is important to explore the effects of coadministration of IV granisetron, given to provide immediate CINV prophylaxis, and GTDS, given to provide extended exposure starting from 24 hours. ${ }^{12}$ The possibility of consecutive GTDS patch use is relevant when chemotherapy regimens last longer than 5 days, as happens with ifosfamide when administered in a 14-day course, or when oral therapies are administered on a continuous basis. ${ }^{24}$ In such instances, the ability to apply consecutive GTDS patches as needed would provide an invaluable treatment option.

\section{Methods}

Sixteen healthy Caucasian subjects ( 8 men and 8 women) with a mean age of 31.1 years (SD $8.1 \mathrm{y}$ ) participated in the study. In a single-center, open-label, single-arm study of 12 healthy volunteers (NCT00873197), all subjects were admitted to the clinic the day before the first dose (day 1) and underwent baseline assessments, including blood sampling, physical examination, and vital signs. All subjects received GTDS (applied to the upper arm) on day 1, followed immediately by IV granisetron ( $1 \mathrm{mg} / \mathrm{mL}$ injection; $0.01 \mathrm{mg} / \mathrm{kg}$, single IV dose administered over 30 seconds). Subjects remained resident until 12 hours after drug administration for pharmacokinetic blood sampling (at 0.05, 0.25, 1, 4, 8 , and 12 hours) and safety assessments and returned for patch adhesion assessments and further pharmacokinetic blood sampling and safety assessments for up to 168 hours postadministration. Blood samples were obtained at 24, 48, 96, and 168 hours postdosing. On day 8 (168 hours), subjects were readmitted to the clinic and the first GTDS patch was removed and a second GTDS patch was applied on the opposite arm. Additional blood samples were obtained $174,180,192,216,264$, and 336 hours postdosing. On day 15 (336 hours postdosing), the second patch was removed. 
Table 3 Plasma pharmacokinetic parameter estimates of granisetron after administration of GTDS with or without external heat

\begin{tabular}{|c|c|c|c|c|c|c|c|}
\hline \multirow[t]{2}{*}{ Treatment } & \multirow[t]{2}{*}{$\mathbf{n}$} & \multicolumn{4}{|c|}{ Geometric mean (CV\%) } & \multirow{2}{*}{$\begin{array}{l}t_{\text {max, }} \text {, hour } \\
\text { median (range) }\end{array}$} & \multirow{2}{*}{$\begin{array}{l}\mathbf{t}_{1 / 2} \text { hour } \\
\text { mean (SD) }\end{array}$} \\
\hline & & $\begin{array}{l}\text { AUC }_{0-\infty} \\
(\mathrm{ng} \cdot \mathrm{h} / \mathrm{mL})\end{array}$ & $\begin{array}{l}\text { AUC }_{0-z} \\
(\mathrm{ng} \cdot \mathrm{h} / \mathrm{mL})\end{array}$ & $\begin{array}{l}C_{\max } \\
(n g / m L)\end{array}$ & $\begin{array}{l}C_{\text {avg }} \\
(\mathrm{ng} / \mathrm{mL})\end{array}$ & & \\
\hline GTDS alone & 16 & $682.1(42.0)^{\mathrm{a}}$ & $574.0(76.1)$ & $6.14(82.7)$ & $4.32(78.4)$ & $54.00(48.00,96.05)$ & $25.16(3.72)^{\mathrm{a}}$ \\
\hline GTDS + external heat & 16 & $628.4(69.9)^{\mathrm{b}}$ & $606.6(65.7)$ & $7.25(52.1)$ & $4.46(65.2)$ & $53.00(27.00,96.03)$ & $30.73(10.06)^{b}$ \\
\hline
\end{tabular}

Notes: ${ }^{a} n=13 ;{ }^{b} n=14$.

Abbreviations: $\mathrm{AUC}_{0-\infty}$, area under the concentration-time curve from time 0 to infinity; $\mathrm{AUC}_{0-\mathrm{z}}$, area under the concentration-time curve from time 0 to the time point of the last quantifiable concentration; $\mathrm{C}_{\text {avg }}$, average plasma concentration; $\mathrm{C}_{\max }$, maximum plasma concentration; CV, coefficient of variation; $\mathrm{GTDS}$, granisetron transdermal system; $n$, number of subjects; $t_{\max }$, time to maximum plasma concentration; $t_{1 / 2}$, elimination half-life.

Subjects were allowed to leave after 12 hours (ie, $180 \mathrm{~h}$ after first dosing) and returned for further assessments up to 336 hours after first administration. The total duration of time from screening through study completion for each subject did not exceed 7 weeks. Poststudy medical evaluations were performed on the last day of the study, after the final assessment.

\section{Results}

Six men and six women, all Caucasian, with a mean age of 29.3 years (SD 6.4 years), participated in the study. Plasma concentration-time profiles for patients who were coadministered IV granisetron and the GTDS and were given a second consecutive GTDS application showed rapid distribution of granisetron after the IV dose, a second concentration peak at 48 hours (presumably attributable to the first GTDS), and a third peak at 216 hours (presumably attributable to the second GTDS; Figure 2). ${ }^{25}$ Median $t_{\max (0-<24)}$ was observed at 0.16 hours, showing rapid distribution of granisetron after IV dosing. The mean apparent $t_{1 / 2}$ estimate was 73.77 hours. While mean granisetron concentrations declined rapidly up to 12 hours postdose, some absorption of granisetron from the GTDS continued during this time, resulting in sustained mean concentrations of granisetron over the 24 hours after IV

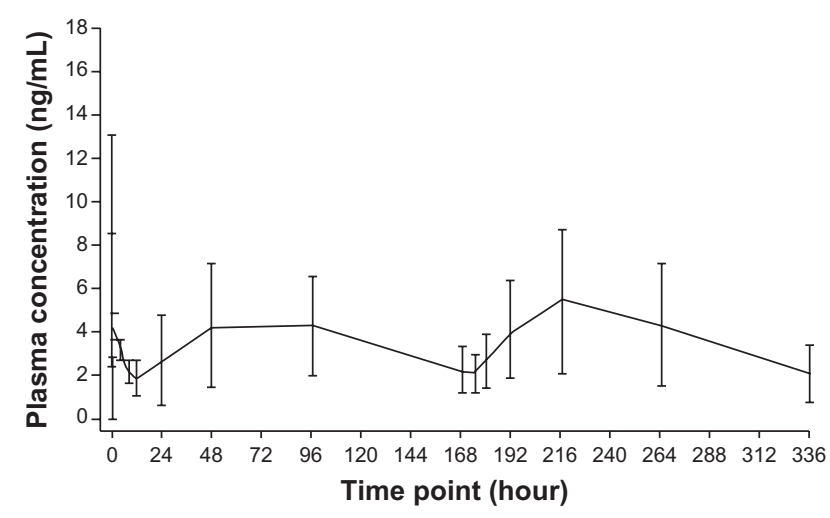

Figure 2 Granisetron plasma concentrations (mean $\pm S D$ ) after coadministration of intravenous granisetron and the granisetron transdermal system (GTDS) application and a subsequent second GTDS application. ${ }^{25}$ and transdermal administration. Peak plasma concentrations were observed 48 hours after both GTDS applications.

Minimal granisetron accumulation occurred after the second GTDS application (Table 4). ${ }^{25}$ Systemic exposure to granisetron was comparable after the first and second GTDS applications, as shown by the minimal differences between $\mathrm{C}_{\max (24-168)}$ and $\mathrm{C}_{\max (168-336)}$ and between corresponding $\mathrm{C}_{\text {avg }}$ estimates, with minimal evidence of accumulation after repeated dosing. In this study, GTDS and IV granisetron coadministration was well tolerated and showed no evidence of increased granisetron-related toxicity during the first 24 hours.

\section{Conclusion}

Minimal granisetron accumulation in plasma was observed after application of a second GTDS patch, suggesting that consecutive GTDS patch application is feasible if clinically warranted. Coadministration of IV granisetron with the GTDS also appears feasible when both immediate and extended CINV management is required.

Table 4 Plasma pharmacokinetic parameter estimates after coadministration of the GTDS and IV granisetron ${ }^{22}$

\begin{tabular}{|c|c|}
\hline $\begin{array}{l}\text { Pharmacokinetic } \\
\text { parameter }\end{array}$ & $\begin{array}{l}\text { GTDS + IV granisetron, } \\
\text { geometric mean (geometric CV\%) } \\
(n=I 2)\end{array}$ \\
\hline $\mathrm{AUC}_{0-\infty}(\mathrm{ng} \cdot \mathrm{h} / \mathrm{mL})$ & $1708(32.0)^{\mathrm{a}}$ \\
\hline$A \cup C_{0-168}(\mathrm{ng} \cdot \mathrm{h} / \mathrm{mL})$ & $509.7(70.0)$ \\
\hline $\mathrm{AUC}_{(0-z)}(\mathrm{ng} \cdot \mathrm{h} / \mathrm{mL})$ & $1032(83.6)$ \\
\hline$C_{\max (0-<24)}(\mathrm{ng} / \mathrm{mL})$ & $7.79(64.1)$ \\
\hline$C_{\max (24-168)}(\mathrm{ng} / \mathrm{mL})$ & $4.12(78.3)$ \\
\hline$C_{\max (>168-336)}(\mathrm{ng} / \mathrm{mL})$ & $4.47(102.0)$ \\
\hline$C_{\text {avg }(0-24)}(n g / m L)$ & $2.50(36.8)$ \\
\hline$C_{\text {avg(0-168) }}(\mathrm{ng} / \mathrm{mL})$ & $3.03(70.0)$ \\
\hline$C_{\text {avg }(0-336)}(\mathrm{ng} / \mathrm{mL})$ & $3.07(83.6)$ \\
\hline \multicolumn{2}{|c|}{$\begin{array}{l}\text { Note: }{ }^{a} n=6 . \\
\text { Abbreviations: } A \cup C_{0-\infty} \text {, area under the concentration-time curve from time } 0 \text { to } \\
\text { infinity; } A \cup C_{0-2} \text {, area under the concentration-time curve from time } 0 \text { to the time } \\
\text { point of the last quantifiable concentration; } C_{\text {avg, }} \text { average plasma concentration; } C_{\max } \\
\text { maximum plasma concentration; } C V \text {, coefficient of variation; GTDS, granisetron } \\
\text { transdermal system; IV, intravenous; n, number of subjects. }\end{array}$} \\
\hline
\end{tabular}




\section{Discussion and conclusion}

The pharmacokinetic profile of GTDS demonstrates that the patch provides sustained delivery and absorption of granisetron over 7 days ${ }^{18}$ and that coadministration of IV granisetron and GTDS (as well as consecutive patch applications) provides immediate and extended protection against CINV with minimal evidence of accumulation; however, no clinical safety or efficacy data are currently available to support this approach. The studies reported here also demonstrated no significant effect of age, BMI, or heat on the pharmacokinetics of transdermally delivered granisetron. Moreover, indirect comparison of separate pharmacokinetic studies has shown that granisetron absorption through the skin of the abdomen does not appear to be notably different from absorption through the skin of the upper arm. The transdermal system delivers sufficient granisetron to provide control of CINV similar to that resulting from multiple daily oral granisetron administrations.

GTDS is effective for the prevention of CINV in patients receiving moderately or highly emetogenic chemotherapy and offers patient adherence and administration advantages over oral and IV antiemetics. It is particularly suitable for multiday chemotherapy regimens owing to its sustained delivery and absorption over multiple days. ${ }^{18}$ Given the availability of antiemetics in IV, oral, and now the GTDS formulations, antiemetic therapy can be tailored to the temporal pattern of onset and the emetic potential of each chemotherapy regimen, diminishing the incidence and severity of CINV,${ }^{12}$ including the frequency of breakthrough and refractory emesis. The GTDS is an effective alternative to oral agents, for which repeated daily administration is required for the control of CINV during a multiday chemotherapy regimen.

\section{Acknowledgments}

The authors wish to thank Yvonne E Yarker PhD CMPP and Thalia Gray $\mathrm{PhD}$ for medical writing assistance in the development of this manuscript. The authors also thank Ann Yellowlees $\mathrm{PhD}$ for statistical work on the tricep skinfold thickness analysis.

\section{Disclosure}

The trials reported here, for which NCT numbers were provided, were sponsored by ProStrakan, Inc. Medical writing, editing, and graphics assistance was provided by Peloton Advantage, LLC and was funded by ProStrakan, Inc. Sally Haislip and James W Gilmore received a grant on behalf of Georgia Cancer Specialists from ProStrakan, Inc, to conduct research on granisetron transdermal system in patients with chemotherapy-induced nausea and vomiting. Julian Howell is an employee of ProStrakan, Inc. The authors report no other conflicts of interest in this work.

\section{References}

1. Grunberg SM. Chemotherapy-induced nausea and vomiting: prevention, detection, and treatment - how are we doing? J Support Oncol. 2004;2(Suppl 1):1-10.

2. Morrow GR, Roscoe JA, Hickok JT, Andrews PR, Matteson S. Nausea and emesis: evidence for a biobehavioral perspective. Support Care Cancer. 2002;10(2):96-105.

3. Schwartzberg LS. Chemotherapy-induced nausea and vomiting: clinician and patient perspectives. J Support Oncol. 2007;5(2 Suppl 1): $5-12$.

4. Schnell FM. Chemotherapy-induced nausea and vomiting: the importance of acute antiemetic control. Oncologist. 2003;8(2):187-198.

5. Naeim A, Dy SM, Lorenz KA, Sanati H, Walling A, Asch SM. Evidence-based recommendations for cancer nausea and vomiting. J Clin Oncol. 2008;26(23):3903-3910.

6. Neymark N, Crott R. Impact of emesis on clinical and economic outcomes of cancer therapy with highly emetogenic chemotherapy regimens: a retrospective analysis of three clinical trials. Support Care Cancer. 2005;13(10):812-818.

7. Sancuso ${ }^{\circledR}$ (granisetron transdermal system) [package insert]. Bedminster, NJ: ProStrakan Inc; 2008.

8. Tuca A. Use of granisetron transdermal system in the prevention of chemotherapy-induced nausea and vomiting: a review. Cancer Manag Res. 2009;2:1-12.

9. Antonopoulos MS, Caspi A. Sancuso ${ }^{\circledR}$ (granisetron transdermal delivery system): a new formulation for chemotherapy-induced nausea and vomiting. P\&T Product Profiler. 2008;33(10):1-31.

10. Kytril (granisetron hydrochloride) tablets [package insert]. Nutley, NJ: Roche Laboratories Inc; 2010.

11. Kytril (granisetron hydrochloride) injection, for intravenous use [package insert]. South San Francisco, CA: Genentech USA Inc; 2011.

12. National Comprehensive Cancer Network. NCCN Clinical Practice

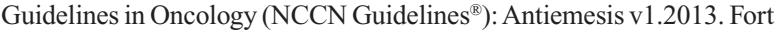
Washington, PA: National Comprehensive Cancer Network; 2012.

13. Basch E, Prestrud AA, Hesketh PJ, et al. Antiemetics: American Society of Clinical Oncology clinical practice guideline update. J Clin Oncol. 2011;29(31):4189-4198.

14. Boccia RV, Gordan LN, Clark G, Howell JD, Grunberg SM; Sancuso Study Group. Efficacy and tolerability of transdermal granisetron for the control of chemotherapy-induced nausea and vomiting associated with moderately and highly emetogenic multi-day chemotherapy: a randomized, double-blind, phase III study. Support Care Cancer. 2011;19(10):1609-1617.

15. Zofran ${ }^{\circledR}$ (ondansetron hydrochloride) injection for intravenous use [package insert]. Research Triangle Park, NC: GlaxoSmithKline Inc; 2012.

16. Anzemet ${ }^{\circledR}$ tablets (dolasetron mesylate) [package insert]. Bridgewater, NJ: sanofi-aventis US LLC; 2011.

17. Mason JW, Selness DS, Moon TE, O’Mahony B, Donachie P, Howell J. Pharmacokinetics and repolarization effects of intravenous and transdermal granisetron. Clin Cancer Res. 2012;18(10):2913-2921.

18. Howell J, Smeets J, Drenth HJ, Gill D. Pharmacokinetics of a granisetron transdermal system for the treatment of chemotherapy-induced nausea and vomiting. J Oncol Pharm Pract. 2009;15(4):223-231.

19. Field KM, Kosmider S, Jefford M, et al. Chemotherapy dosing strategies in the obese, elderly, and thin patient: results of a nationwide survey. $J$ Oncol Pract. 2008;4(3):108-113.

20. Guillory G, Howell J, Yellowlees A. Effects of age, body mass index, and tricep skinfold thickness on the pharmacokinetics of granisetron transdermal system [abstract]. J Support Oncol. 2011;9(5):A-9-A-10. 
21. Shomaker TS, Zhang J, Ashburn MA. A pilot study assessing the impact of heat on the transdermal delivery of testosterone. J Clin Pharmacol. 2001;41(6):677-682.

22. Shomaker TS, Zhang J, Ashburn MA. Assessing the impact of heat on the systemic delivery of fentanyl through the transdermal fentanyl delivery system. Pain Med. 2000;1(3):225-230.

23. Barkve TF, Langseth-Manrique K, Bredesen JE, Gjesdal K. Increased uptake of transdermal glyceryl trinitrate during physical exercise and during high ambient temperature. Am Heart J. 1986;112(3):537-541.
24. Meazza C, Casanova M, Luksch R, et al. Prolonged 14-day continuous infusion of high-dose ifosfamide with an external portable pump: feasibility and efficacy in refractory pediatric sarcoma. Pediatr Blood Cancer. 2010;55(4):617-620.

25. Howell J, O’Mahony B, Gutierrez-Eateinou R. Co-administration of transdermal granisetron and intravenous (IV) granisetron in healthy subjects: a phase I pharmacokinetic, tolerability and safety study [abstract PA-01]. 5th Annual Chicago Supportive Oncology Conference; October 1-3, 2009; Chicago, IL, USA.

\section{Publish your work in this journal}

Research and Reports in Transdermal Drug Delivery is an international, peer-reviewed, open access online journal publishing original research, study protocols, reviews, editorials and commentaries on all aspects of transdermal drug delivery. Specific topics in the journal include: Laboratory and clinical development of drug delivery systems including preclinical, clinical studies and protocols; Rationale and basic science; Drug delivery via gels, creams or patches; Use of chemical drug penetration enhancers ; Patient acceptability studies; and pharmacoeconomic and clinical outcome studies. The manuscript management system is completely online and includes a very quick and fair peer-review system, which is all easy to use. Visit http://www.dovepress.com/ testimonials.php to read real quotes from published authors.

Submit your manuscript here: http://www.dovepress.com/research-and-reports-in-transdermal-drug-delivery-journal 